\title{
PROJETO DE HABITAÇÃO SOCIAL EM ÁREA DE LAZER EM PRESIDENTE PRUDENTE-SP - ESTUDO DE CASO
}

Mariana Malheiro Negrão Bandeira', Karen Staquecini Martinês ${ }^{1}$, Sibila Corral de Arêa Leão Honda $^{2}$, Marcela do Carmo Vieira ${ }^{2}$

${ }^{1}$ Discente do curso de Arquitetura e Urbanismo da Universidade do Oeste Paulista - UNOESTE. ${ }^{2}$ Docente do curso de Arquitetura e Urbanismo da Universidade do Oeste Paulista - UNOESTE.

\section{RESUMO}

As políticas e os programas habitacionais brasileiros, desde a década de 1930, têm demonstrado ineficiência no combate ao déficit de moradias sociais. O Programa de Ação Imediata para Habitação (PAIH), do Governo do então Presidente Fernando Collor de Mello, tinha como meta a eliminação desse déficit em 180 dias. Em Presidente Prudente-SP, alguns conjuntos habitacionais foram executados por meio desse programa. Assim, este artigo busca contribuir para uma analise critica sobre a produção da habitação de baixa renda em cidades medias, considerando a estrutura urbana onde se localizam os empreendimentos habitacionais. Tem-se como estudo de caso o conjunto habitacional Santa Paula, executado com financiamento do Programa de Ação Imediata para Habitação (PAIH), do Governo Federal em 1992, em Presidente Prudente. A metodologia esta embasada em pesquisa teórica e conceitual, documental e de campo, com mapeamentos, e relacionando todas as informações levantadas.

Palavras-chave: Expansão Urbana, Projeto Urbano, Projeto Arquitetônico, Segregação Urbana, Habitação Social.

\section{INTRODUÇÃO}

Com o início do processo de industrialização brasileira, tem ocorrido forte êxodo em direção aos centros urbanos, principalmente os mais desenvolvidos, gerando grande inchaço populacional nas cidades. No entanto, a partir da década de 1960, essa realidade se pode ser mais sentida, inclusive cidades do interior do país, e de porte médio.

Essa realidade tem sido acompanhada por falta de estrutura urbana para absorção desse contingente populacional, resultando em forte déficit habitacional urbano. Ao mesmo tempo, políticas públicas voltadas ao embelezamento e à instalação de infraestrutura urbana incentivaram a expulsão da população carente, direcionando-a às periferias, inclusive para áreas clandestinas (MARQUES e TORRES, 2005; BONDUKI, 2004).

Aliado a isso, fortes processos de segregação intra-urbana têm ocorrido nas cidades brasileiras, motivados principalmente por questões sociais e econômicas (VILLAÇA, 1999).

Durante a "Era Vargas" (1930-1945), no entanto, o Estado brasileiro começou a buscar alternativas para a redução do déficit de moradia por meio de ações diretas, como Carteiras 
Prediais dos Institutos de Aposentadoria e Previdência (IAP's), criadas em 1938, que seriam as responsáveis pela construção e financiamento de novas unidades habitacionais nos centros urbanos. Esse órgão foi base para a criação da Fundação da Casa Popular, em 1946, no Governo do Presidente Eurico Gaspar Dutra.

No início da década de 1960, durante o Governo de Jânio Quadros, foi feita uma reestruturação na política habitacional por meio do Plano de Assistência e da criação do Instituto Brasileiro de Habitação (IBH), mas que não obtiveram sucesso devido ao acelerado processo de urbanização no país que gerava constante crescimento da demanda por moradias (HONDA, 2011).

No entanto, o padrão de expansão territorial urbana periférica foi consolidado, baseado na autoconstrução de moradias em terrenos clandestinos, desprovidos de infraestrutura e de serviços públicos. Verifica-se também processo de verticalização urbana e de incremento nas vias de circulação de automóveis particulares, como o Plano de Avenidas de São Paulo (KOWARICK e BONDUKI, 1994; VILLAÇA, 1999).

Em 1964, com o Regime Militar, a política habitacional vigente foi rejeitada, e a nova visava a "facilitar o acesso à casa própria, por meio da construção de habitações populares e da eliminação das favelas, auxiliar a recuperação da economia e favorecer a estabilidade social" (HONDA, 2011, p.22). Foram criados o Sistema Financeiro de Habitação (SFH) e o Banco Nacional da Habitação (BNH).

De forma geral, os locais em que conjuntos habitacionais eram executados se situavam na franja urbana ou além da malha, e sem infraestrutura ou equipamentos urbanos, surgindo sérios problemas para os moradores e para os Governos municipais. Esse padrão perdurou desde a década de 1930 até os primeiros anos da década de 1990, com os programas do Governo Fernando Collor de Melo, e foi retomado no Governo do Presidente Luís Inácio Lula da Silva, com a justificativa de aquisição de terras mais baratas para investimento em habitação social.

Em 1986, o BNH foi extinto, e, em 1987, foi retomada a discussão sobre reforma urbana e a questão da habitação. Em 1988 a nova Constituição Federal foi sancionada. A Constituição Estadual Paulista foi aprovada no ano seguinte, ano que também foi criada a Companhia de Desenvolvimento Habitacional e Urbano (CDHU), da Secretaria de Habitação do Estado de São Paulo (HONDA, 2011).

A partir 1990 até 1992, durante o Governo do Presidente Fernando Collor de Melo, nova política habitacional foi proposta apoiada na criação de novos programas, baseados nos recursos do Fundo de Garantia por Tempo de Serviço (FGTS), mas com características diversas entre si. O 
Programa de Ação Imediata para Habitação (PAIH) foi lançado em 1990, almejando a construção de aproximadamente 245 mil unidades habitacionais em caráter emergencial, em prazo de 180 dias, voltadas a famílias com renda de até cinco (5) salários mínimos, com execução por construtoras privadas (BOTEGA, 2007; EMILIANO, 2006; FREITAS, 2004).

Esse programa apresentava três modalidades: o Programa de Moradias Populares (PMP), onde seriam entregues unidades acabadas mas sem infraestrutura urbana, o Programa de Lotes Urbanizados e Cesta Básica e o Programa de Ação Municipal para Habitação Popular, com unidades acabadas em área urbanizada (LIMA, 2007; FREITAS, 2004).

O resultado geral dessas ações federais foi o esgotamento dos recursos, e redução total de novos investimentos entre os anos seguintes - 1993 e 1994. Assim, não houve prosseguimento com do programa. Nesse último ano, com a implantação do Plano Real e a estabilização da economia do país, foi possível retomar os investimentos na área habitacional.

Em 1995, com o novo Governo Federal, tendo sido eleito Fernando Henrique Cardoso, foi divulgada nova política de habitação, buscando-se a descentralização da execução dos projetos e visando a programas voltados às questões quantitativas e qualitativas, com implantação em áreas urbanizadas. No início de 2003, o Presidente Luís Inácio Lula da Silva tomou posse, alguns programas foram mantidos e outros criados (HONDA, 2011).

Baseado neste contexto, esta pesquisa busca analisar a produção da habitação social, tendo como foco a cidade de Presidente Prudente-SP, sua ação indireta na produção da urbanização por meio de sua implantação na estrutura urbana e da tipologia das edificações executadas, tendo como estudo de caso o conjunto habitacional Santa Paula, financiado pelo Programa de Ação Imediata para Habitação (PAIH), em 1992.

\section{METODOLOGIA}

A metodologia utilizada nesta pesquisa está baseada em aprofundamento teórico; investigação prática, com análise do caso estabelecido, por meio de pesquisa documental, levantamentos de campo e mapeamentos; e análises e elaboração do corpo de argumentação.

\section{PRESIDENTE PRUDENTE - ANÁLISE URBANA E HABITAÇÃO SOCIAL}

Presidente Prudente é município paulista, localizado na região oeste do estado, na Alta Sorocabana. Sua colonização se deve diretamente à implantação de estação ferroviária da Estrada de Ferro Sorocabana, inaugurada em 1919, e produção agropecuária. Em relação à estrutura 
urbana, seu início também foi dependente da estação, por meio da abertura de dois loteamentos: Vila Goulart e Vila Marcondes, cujas implantações ladeavam a referida estação. Em 1921, o município foi criado legalmente.

Durante as quatro primeiras décadas (1920 a 1950), a cidade apresentou significativa expansão territorial, sem planejamento e sem regularização legal; tendo havido redução na velocidade de crescimento espacial urbano na década seguinte. $E$, no início do período do Regime Militar, retoma-se aumento da população, com ampliação do quadro industrial e desenvolvimento das atividades terciárias (HONDA, 2000).

Em 1968 foi elaborado o primeiro plano diretor municipal para Presidente Prudente, o Plano Diretor de Desenvolvimento Integrado (PDDI), com metodologia do Serviço Federal de Habitação e Urbanismo (SERFHAU) (HONDA, 2011).

No processo de produção do espaço urbano em Presidente Prudente, vários conjuntos habitacionais foram construídos, com o primeiro executado em 1968, com financiamento do BNH. Até o ano de 1982, mais dez conjuntos foram entregues. Nos anos seguintes ocorreu paralização de investimentos na área, com retomada em 1989 (TORREZAN, 1992; MARISCO, 2003; FERNANDES, 1998).

Durante os anos de 1990-1991-1992, nove conjuntos habitacionais foram aprovados, incluindo financiamentos do PAlH: Ana Jacinta, com 2500 unidades, Jardim Vale do Sol, com 183 unidades, e Jardim Santa Paula, com 74 unidades residenciais, foco desta pesquisa. Entre 1993 e 1996 houve aprovação de loteamentos municipais com dação em uso; e entre 1997 e 1999, mais doze empreendimentos foram construídos. A partir desses dados, verifica-se a construção de mais de 15.000 unidades habitacionais na cidade (HONDA, 2011).

Desse modo, pode-se observar que há grande relevância em relação à construção de moradia popular em Presidente Prudente, influenciando fortemente toda a estrutura urbana existente, estimulando a expansão urbana para determinados setores urbanos, assim como reforçando processos de segregação socioespacial urbanos.

\section{JARDIM SANTA PAULA}

O Jardim Santa Paula é um loteamento urbano, localizado na região oeste da malha de Presidente Prudente (Figura 1). Foi aprovado junto à Secretaria de Planejamento municipal em novembro de 1979, conforme consta na planta do processo de aprovação. O projeto do loteamento disponibilizou 377 lotes urbano, além das áreas institucional e de lazer (Figura 2). 


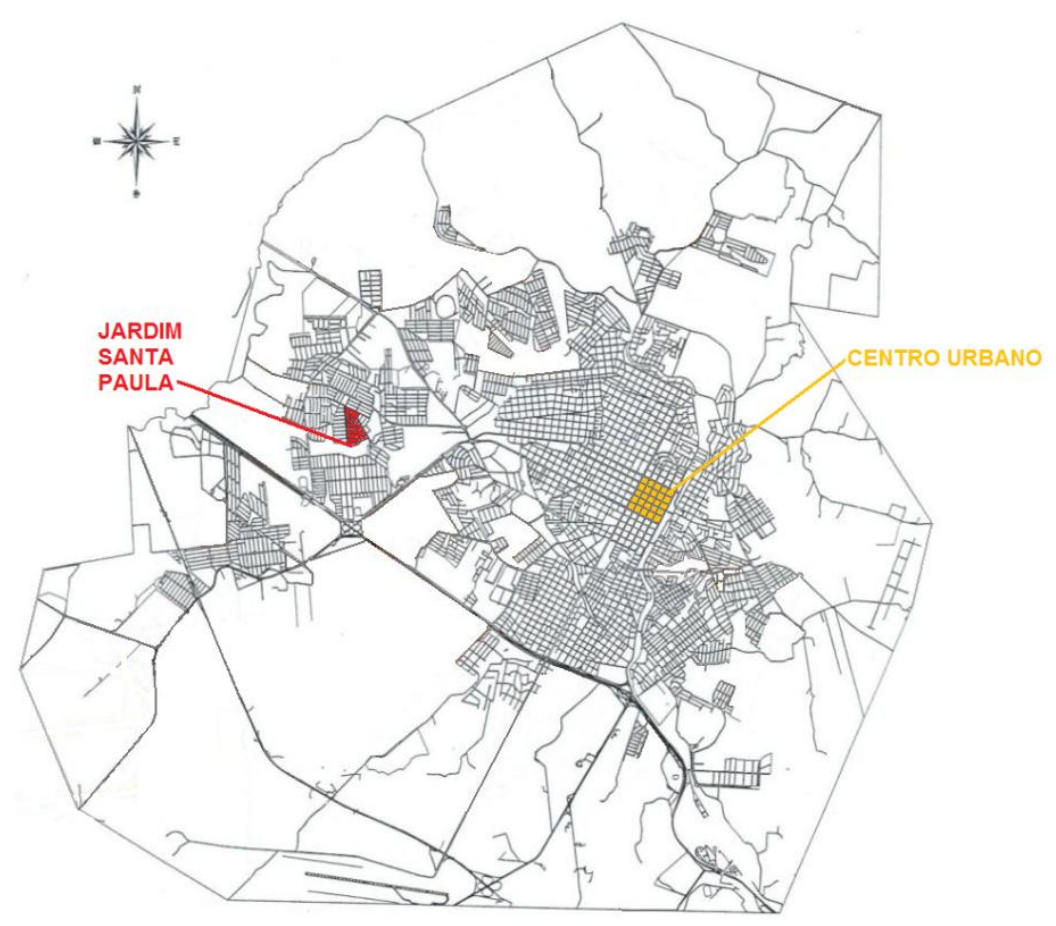

Figura 1. Planta da malha urbana de Presidente Prudente em 1992 - localização do loteamento Jardim Santa Paula

Fonte: Prefeitura Municipal de Presidente Prudente, 2013

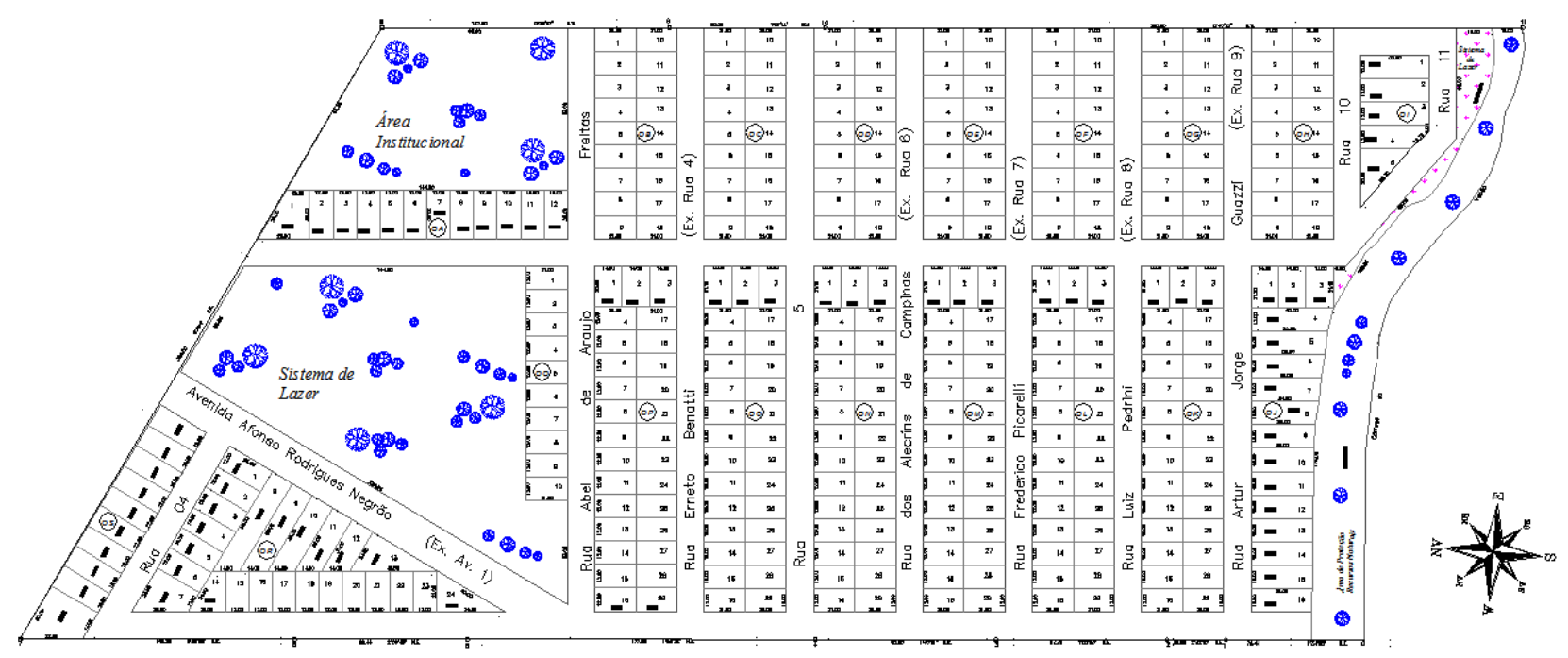

Figura 2. Loteamento Jardim Santa Paula aprovado

Fonte: Prefeitura Municipal de Presidente Prudente, 2013

O conjunto habitacional Santa Paula, foco desta pesquisa, foi executado no Jardim Santa Paula, loteamento já existente à época da aprovação do financiamento habitacional (1992). A Prefeitura Municipal participou do projeto por meio de doação do solo urbano para implantação do empreendimento. 
Interessante notar, no entanto, que a área entregue para implantação do conjunto habitacional, assim como em outros conjuntos de habitação de interesse social nesta cidade, foi área de lazer do loteamento aprovado (Figura 3).

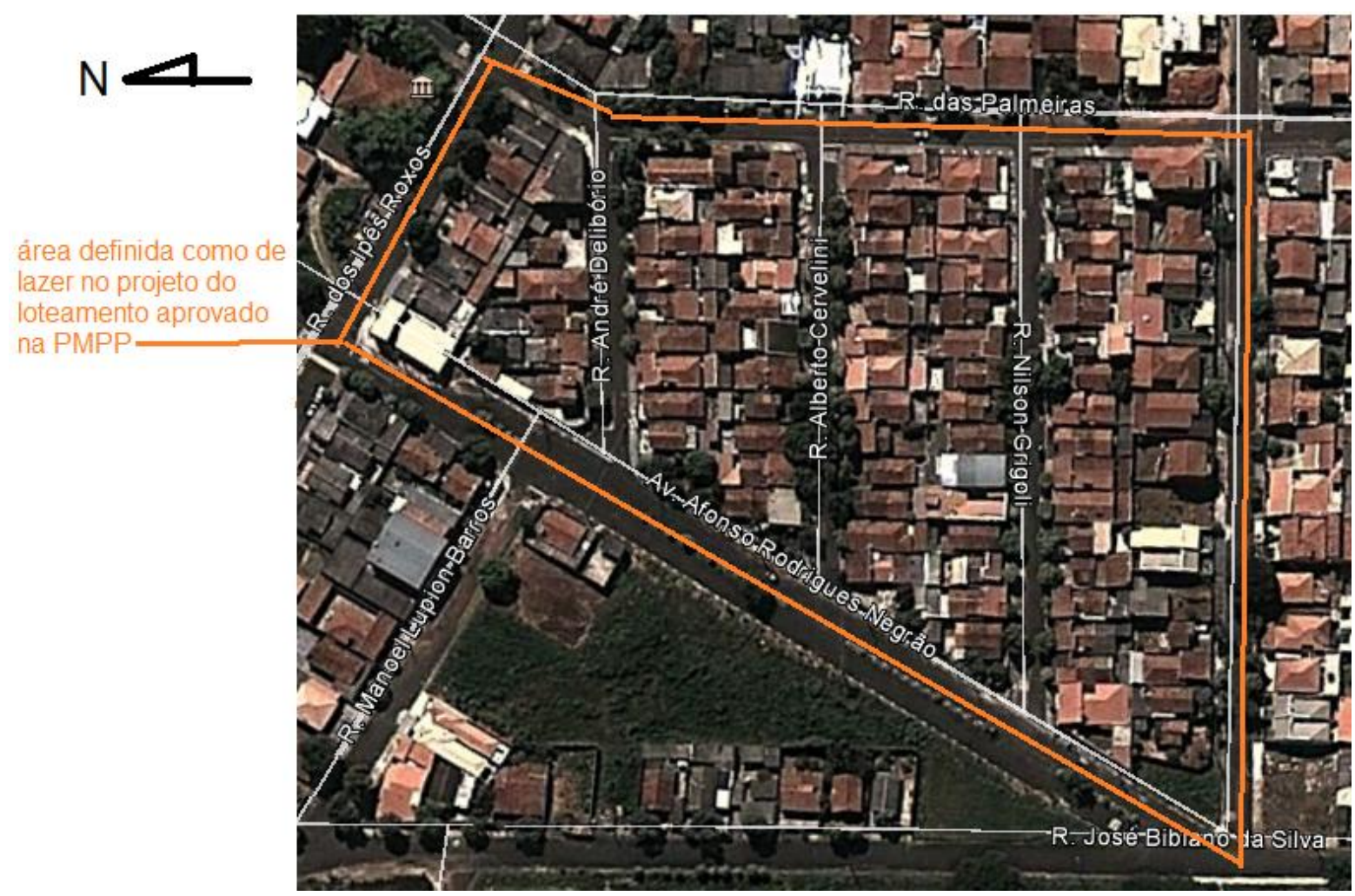

Figura 3. Conjunto habitacional implantado na área de lazer aprovada no loteamento urbano Fonte: Google Earth, 2013

O empreendimento de moradias sociais é formado por 74 unidades unifamiliares, com 29,28 ² $^{2}$ cujo projeto base é composto por um dormitório, banheiro, sala e cozinha (Figura 4).

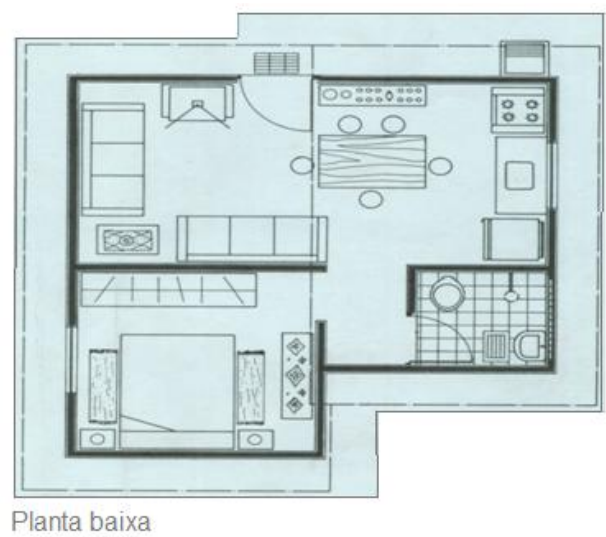

Figura 4. Planta das unidades habitacionais

Fonte: Manual do Proprietário 
Focando no conjunto habitacional aprovado em 1992 e financiado pelo Governo Federal por meio do PAIH, sem levar em conta o sério problema de alteração de uso e ocupação do solo urbano por meio de sua implantação em área de lazer, verifica-se que, após 21 anos da entrega aos beneficiados, esse empreendimento apresenta apenas $32,4 \%$ das unidades com alterações bastante marcantes, mantendo-se as características originais de conjunto de habitação social.

Sua implantação em área consolidada na estrutura urbana, mesmo que com concentração de moradia de população de baixa renda familiar, estimulando-se a segregação socioespacial pela homogeneidade, demonstra maior possibilidade de fixação e interesse da população beneficiada na região.

Embora o programa habitacional financiador (PAlH) não propusesse a execução dos conjuntos habitacionais em áreas urbanas servidas de comércio, serviços e equipamentos públicos, no caso do Santa Paula, isso ocorreu, possibilitando a inclusão social de seus moradores.

\section{CONSIDERAÇÕES FINAIS}

Por meio desta pesquisa, pode-se verificar que a cidade de Presidente Prudente, embora disponibilizando incorretamente área de lazer para execução de habitação de interesse social, possibilitou a inclusão social do moradores do conjunto analisado.

A capacidade de maior acesso a serviços e equipamentos públicos dos moradores do empreendimento de moradia social resulta em beneficio a toda cidade, reduzindo-se custos de novos investimentos.

Apesar disso, o inadequado local de implantação torna um benefício em prejuízo social devido à falta de áreas de lazer e de permeabilidade urbana.

Observa-se assim que as análises sociais, econômicas, ambientais, entre outras, que precisam ser feitas na elaboração de projetos e nos processos de planejamento e gestão urbanos são muito importantes, cuja identificação de um benefício pode resultar em algum prejuízo social.

\section{REFERÊNCIAS}

BONDUKI, N. Origens da habitação social no Brasil: arquitetura moderna, lei do inquilinato $e$ difusão da casa própria. $4^{a}$.edição. São Paulo: Estação Liberdade, 2004.

BOTEGA, L.R. De Vargas a Collor: urbanização e política habitacional no Brasil. Espaço Plural, ano VIII, $\quad$ o.17, 20.semestre 2007, p.65-72. Disponível em: http://erevista.unioeste.br/index.php/espacoplural/article/view/1619/1308. Acesso em: 30.mar.2010. 
EMILIANO, E.O. Legislação para Habitação de Interesse Social - estudo de caso do município de Campinas. Campinas: PUC, 2006. (Dissertação de Mestrado).

FERNANDES, S.A.S. Territorialização das políticas habitacionais em Bauru e Presidente Prudente - a atuação da CDHU, COHAB-CRHIS e COHAB-Bauru. Presidente Prudente: UNESP, 1998 (Dissertação de Mestrado).

FREITAS, E.L.H. Como qualificar conjuntos habitacionais populares. Brasília: Caixa Econômica Federal, 2004.

HONDA, S.C.A.L. A centralidade urbana em Presidente Prudente. São Paulo: UPM, 2000 (Dissertação de Mestrado).

HONDA, S.C.A.L. Habitação de Baixa Renda como Produto do Capital - o Programa de Arrendamento Residencial (PAR) em Presidente Prudente-SP. São Paulo: UPM, 2011 (Tese de Doutorado).

KOWARICK, L.; BONDUKI, N. Espaço urbano e espaço político: do populismo à redemocratização. In: KOWARICK, L. (org.). As lutas sociais e a cidade: São Paulo - passado e presente. 2a. edição revisada. São Paulo: Ed. Paz e Terra, 1994. p.147-177.

LIMA, E.C.M. Políticas Federais de Habitação no Brasil (1930-2005): marcos históricos e institucionais. Maceió: Universidade Federal de Alagoas, 2007 (Dissertação de Mestrado).

MARISCO, L.M.O. A norma e o fato: abordagem analítica da segregação sócio-espacial e exclusão social a partir dos instrumentos urbanísticos. Presidente Prudente: FCT-UNESP, 2003 (Tese de Doutorado).

MARQUES, E.; TORRES, H. (org). São Paulo: Segregação, Pobreza e Desigualdades Sociais. São Paulo: Editora SENAC São Paulo, 2005.

TORREZAN, R.M. Reestruturação da cidade: localização de conjuntos habitacionais, estrutura e crescimento urbano em Presidente Prudente. Presidente Prudente: FCT/UNESP, 1992 (Monografia de Graduação).

VILLAÇA, F. Uma contribuição para a história do planejamento urbano no Brasil. In: DÉAK, C; SCHIFFER, S.R (orgs). O Processo de Urbanização no Brasil. São Paulo, EDUSP, 1999, p.169-243. 